Fire Sci. Eng., Vol. 27, No. 6, pp. 77-82, 2013

\title{
$\mathrm{CCD}$ 카메라 영상을 이용한 스마트 화재 영상 인식 시스템
}

\author{
김장원 \\ 가천대학교 에너지IT학과
}

\section{Smart Fire Image Recognition System using Charge-Coupled Device Camera Image}

\author{
Jang-Won Kim \\ Dept. of Energy IT, Gachon University
}

(Received November 20, 2013; Revised December 6, 2013; Accepted December 6, 2013)

요 약

본 연구에서는 유무선 TCP/IP 기능과 Pan/Tilt 기능을 갖는 Charge-Coupled Device (CCD) 카메라를 이용하여 화재 발생 위치를 추적하고, 스마트 모바일 통신 기능을 탑재한 안드로이드 시스템에 실시간으로 정보를 전달하여 원거리에서 화재를 인식하고 재난을 제어할 수 있는 스마트 화재 인식 시스템을 제안하였다. 제안한 방법을 구현하기 위하여 첫째, 입력영상을 hue saturation intensity (HSI) 변환하여 주변 밝기와 잡영상들을 제거하여 순수한 화염만을 분할하는 알고 리즘을 제안하였다. 둘째, Pan/Tilt 기능으로 화재가 발생한 위치를 정확하게 추적하여 적절하게 화재 인식을 할 수 있도 록 하였다. 셋째, 모바일 기능을 탑재한 안드로이드 통신시스템으로 화재상황을 원격지에서도 확인할 수 있는 스마트한 화재 인식 시스템을 구현할 수 있도록 하였다. 제안한 방법을 확인하기 위하여 10 개의 화재 동영상을 입력하고 실험을 수행한 결과 10 개의 동영상에서 화재영역을 분할하고 화재 위치를 모두 추적하였다.

\begin{abstract}
This research suggested smart fire recognition system which trances firing location with CCD camera with wired/wireless TCP/IP function and Pan/Tilt function, delivers information in real time to android system installed by smart mobile communication system and controls fire and disaster remotely. To embody suggested method, firstly, algorithm which applies hue saturation intensity (HSI) Transform for input video, eliminates surrounding lightness and unnecessary videos and segmentalized only firing videos was suggested. Secondly, Pan/Tilt function traces accurate location of firing for proper control of firing. Thirdly, android communication system installed by mobile function confirms firing state and controls it. To confirm the suggested method, 10 firing videos were input and experiment was conducted. As the result, all of 10 videos segmentalized firing sector and traced all of firing locations.
\end{abstract}

Keywords : Fire image recognition, Fire image detection, HSI transform, Smart fire control system

\section{1. 서 론}

정보기술(information technology: IT)의 발전에 의하여 단순한 센서를 활용한 화재 감지가 아닌 영상을 통하여 화 재를 감지하고, 스마트기능을 부여하여 원거리에서도 적절 하게 화재를 진압하거나 화재에 의한 인명피해를 최소화 할 수 있는 연구들이 많이 진행되고 있다.

CCD (charge-coupled device) 카메라를 이용한 영상에서 화재를 인식하고 감지하는 방법으로는 Red Filtering을 이 용한 화재 영상 분할(1) 동영상 내에서 화재 위치의 움직임 변화를 이용한 방법 ${ }^{(2-4)}$, 영상의 히스토그램의 분포를 이용

E-Mail: jwkimm@gachon.ac.kr

TEL: +82-10-9052-5975, FAX: +82-31-750-5588
한 화재 영역 분할 방법 ${ }^{(5)}$, 또한 차분영상 데이터를 이용하 는 시간적 변화에 기반한 방법 () 등등이 연구되어왔다.

차분영상을 이용한 방법은 기존의 Reference영상을 두고 어떤 변화가 생기면 차분영상을 구해서 그 영역이 화재가 발 생하였는지의 여부를 판단하는 방법이고, Red Filtering 방법 은 입력영상의 red green blue (RGB)를 분해하고 그중에서 Red 성분만을 필터링하여 화재 정보를 구분하는 방법이다. 히스토그램을 이용한 방법은 영상의 밝기분포를 확률로 나 타내어 화재에 해당하는 밝기분포가 분포하고 있는지를 화 재 인식의 방법으로 사용하는 것이다. 이러한 $\mathrm{CCD}$ 카메라 를 활용한 화재영상 인식 방법들은 낮은 해상도나 화재가 아

ISSN: $1738-7167$

DOI: http://dx.doi.org/10.7731/KIFSE.2013.27.6.077 
닌 불빛의 간섭에 의하여 오인식이 많았고, 또한 화재 감시 시스템에 사람이 항상 상주해야 하는 불편함이 있었다.

본 연구에서는 이러한 문제점을 극복하고 스마트 기능 을 탑재하여 효율적인 화재감지 및 더 나아가 효과적인 화 재 진압에 도움을 줄 수 있는 시스템을 제안하고자 한다. 기존의 $\mathrm{CCD}$ 카메라와 달리 유무선 $\mathrm{TCP} / \mathrm{IP}$ 기능이 탑재 되고 해상도가 고해상도 수준으로 향상된 $\mathrm{CCD}$ 카메라를 활용 ${ }^{(7)}$ 하여 화재 영역 인식률을 크게 높이고자 하며, Pan/ Tilt 기능을 활용하여 실제 화재가 발생한 곳을 보여줄 수 있도록 할 것이다. 또한 화재 방재 센터를 원거리에서도 운용할 수 있도록 모바일 통신 ${ }^{(8)}$ 을 부여하여, 원거리에서 의 화재 인식 및 미연에 화재를 막을 수 있도록 화재 경보 를 알림, 인명피해 축소를 위해 화재를 효과적으로 판단할 수 있도록 하는 기능들이 탑재되도록 한다. 마지막으로 그 동안의 영상 내에서 화염 부위를 분할하고 인식하는 알고 리즘들은 주변의 불빛이나 다양한 잡음들에 의하여 오인식 될 확률이 높았으나 본 연구에서는 영상을 hue saturation intensity (HSI) 변환하고 요소별로 화재 영역의 색상, 명도 채도가 일반적인 빛의 그것과는 다르다는 점에 착안한 알 고리즘을 제안하여, 화재영역을 추출하고 인식하는 확률을 높이고자 한다.

\section{2. 화재 인식 및 추적 시스템}

\subsection{RGB 영상의 HSI변환}

입력된 영상으로부터 주변 불빛과 화재 불빛을 구별하 기 위하여 HSI(Hue, Saturation, Intensity)변환을 수행한다. Figure 1은 RGB 모델이다 ${ }^{(9)}$. CCD 카메라로 입력되는 $\mathrm{RGB}$ (Red, Green, Blue)영상은 컴퓨터 그래픽스에서 사용 되는 3 차원 직각좌표계이며, 빛의 삼원색을 혼합하여 나타 날 수 있는 빛의 다양성을 보여주고 있다.

Figure 2는 HSI 모델이다. HSI 모델은 인간의 색 인지에 따른 사용자 지향성의 색상 모형이다. $\mathrm{H}$ 는 색상(Hue), $\mathrm{S}$ 는 채도(Saturation), I는 명도(Intensity)이다. 입력된 RGB 값에

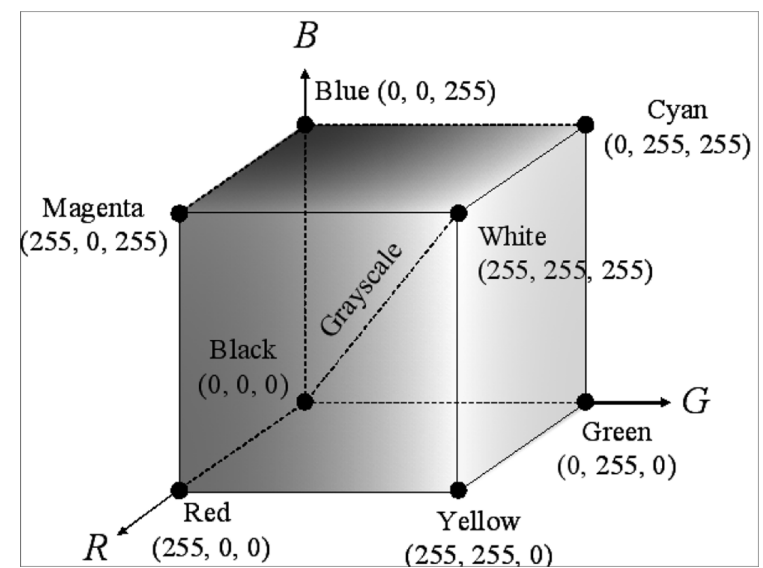

Figure 1. RGB model.

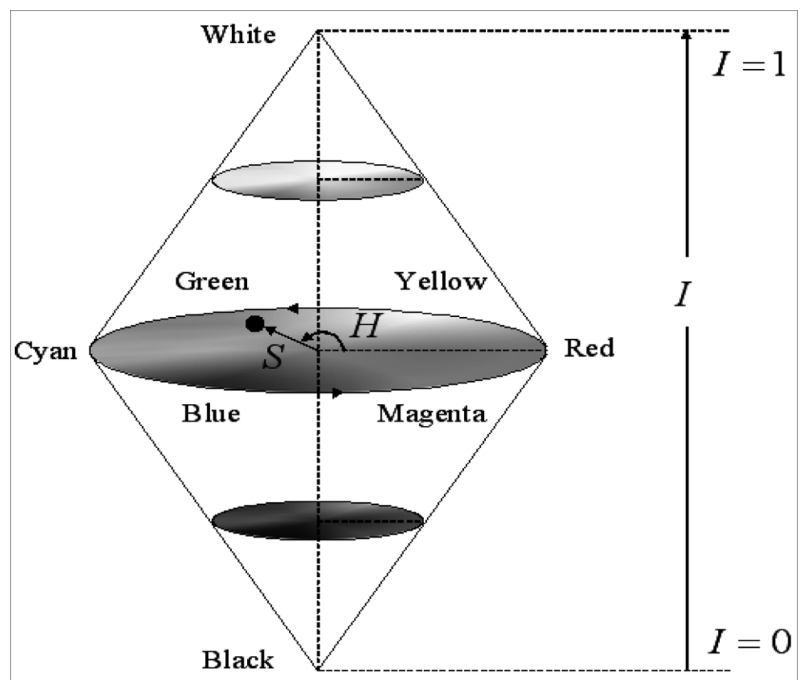

Figure 2. HSI model.

서 다음 식(1), 식(2), 식(3)과 같이 HSI값을 얻을 수 있다 ${ }^{(9)}$.

$$
\begin{aligned}
& H= \begin{cases}\theta & \text { if } B \leq G \\
360-\theta & \text { if } B>G\end{cases} \\
& S=1-\frac{3}{(R+G+B)}[\min (R, G, B)] \\
& I=\frac{1}{3}(R+G+B)
\end{aligned}
$$

여기서 $\theta$ 는 다음식과 같다.

$$
\theta=\cos ^{-1} \frac{\frac{1}{2}[(R-G)+(R-B)]}{\sqrt{(R-G)^{2}+(R+B)(G-B)}}
$$

빛의 밝기(Gray-Level)가 0 255레벨 사이의 값을 갖으 며, 화재가 발생했을 때 이 불꽃의 밝기는 임의의 Threshold 값 이상의 밝기만을 불꽃이라고 인식할 수 있다. 그러나 그 밝기 안에는 화염이 아닌 다른 밝기 값들도 분포하고 있으 므로 이를 제거하기 위하여 RGB영상을 HSI영상으로 변환 하여 다양한 밝기값이 있는 환경에서 화염의 밝기만을 추 출할 수 있다. 실험적으로 주변환경을 고려하여 Threshold 값은 결정되어지며 초기 화재가 발생단계에 있는 경우는 위 식에서 보는바와 같이 $\mathrm{Hue}$ 의 경우 $0^{\circ}$ 와 $360^{\circ}$ 는 같은 위치이며 이것이 붉은색이므로 $0^{\circ}$ 와 $360^{\circ}$ 를 빛의 밝기 255 로 하였다. 반복실험을 통하여 $10^{\circ}$ 범위내에 있는 밝기 가 화염으로 인식하였다.

\section{2 스마트 제어 시스템 구섬}

화재감시시스템의 구성은 최근 모바일 시스템의 발전과 더불어 언제 어디서나 화재를 인식하고 감시할 수 있는 스 


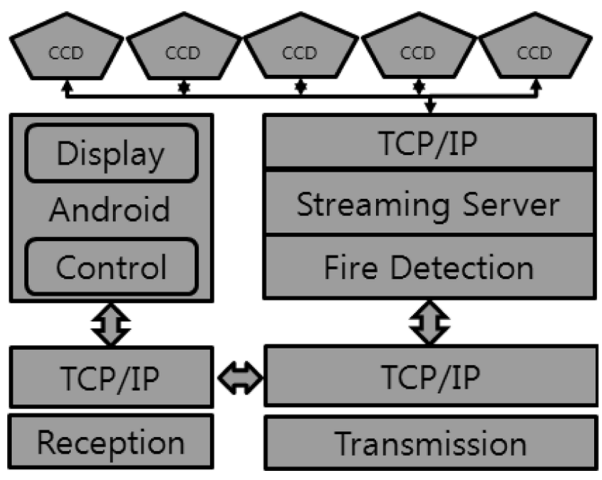

Figure 3. Block diagram of smart control system.

마트 시스템으로 변하고 있다. Figure 3은 본 연구에서 제 안한 스마트 제어 시스템의 블록다이어그램이다.

$\mathrm{CCD}$ 카메라는 최근 IT기술의 발전에 의하여 Zoom-In/ Out 기능은 물론 Pan/Tilt 기능을 탑재하고 있으며, 유/무 선 TCP/IP 통신을 위한 Ethernet이 탑재되어있다. 기존의 카메라와는 달리 Pan/Tile 기능을 통하여 화재의 위치를 추적할 수 있다.

Streaming server와 fire detection에서는 입력영상의 HSI 값을 통하여 화염을 인식한다. Figure 4는 화염을 감 지하고 인식하는 알고리즘을 나타내었다. 입력영상을 RGB 에서 HSI로 변환하고 2진영상(2-Gray-Level Image)으로 변환한 다음 그 영역에서 HSI 변환에서 설명한 바와 같이 화염으로 인식된다면 그 영역의 경계를 검출한다. 검출된 영역의 Viewport 좌표를 추출하고 이를 $\mathrm{CCD}$ 카메라의 $\mathrm{Pan} / \mathrm{Tilt}$ 를 제어하여 화재가 발생한 곳을 Viewport의 정중 앙으로 조준하게 한다.

수신단에서 모바일 통신이 가능한 Android 시스템은 송 신단에서 보내온 화재 영상의 결과를 실시간으로 확인할 수 있으며, 화재인식 알고리즘에 의해서 인식된 상황이 올

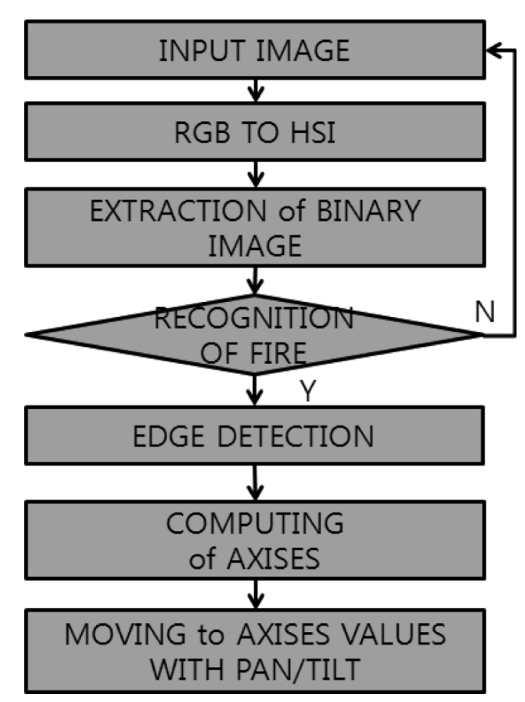

Figure 4. Algorithm of fire recognition.
바른지 아닌지를 확인할 수 있다. 즉, 현장 접근성이 어려 운 상황에서 자동으로 원거리에서 관리자가 제어를 가능 하게 해주는 스마트기능의 역할을 하고 있다.

\section{3. 실험 및 고찰}

\subsection{HSI 변환에 의한 화염 영역 검출(2진영상)}

입력된 영상으로부터 화재 발생 사실을 인지하고, 화재 영역을 HSI 변환을 통해 화재 인식 알고리즘을 적용하여 화재가 발생한 영역이 존재한다면 이 영역을 우선 2진영 상으로 추출하여야 한다. 실험환경은 인위적으로 화재를 일으킬 수 없으므로 화재 발생 초기에 해당하는 상황을 연 출하기 위하여 여러개의 초를 뭉쳐서 화재 초기 발생상태 로 가정하였다. 화재가 이미 크게 번진 상태에서는 화재 인식을 해도 의미가 없으므로 가능한한 화재 발생 초기를 인지하여 적절히 대응할 수 있도록 하였다.

Figure 5는 실험에 사용된 원영상이며 크기는 $680 \times 480$ 이고, True Color를 사용하는 영상이다. 실제는 $\mathrm{CCD}$ 카메 라를 통하여 실시간 동영상으로 입력되나, 초당 30 프레임 중에서 한 개를 추출하여 화재 인식 알고리즘을 적용한다. 화재 인식 및 추적을 위하여 하나의 화재 상황에 대하여 총 16 프레임이 사용되었으며, 그중 15 번째 프레임이다.

Figure 6은 원영상으로부터 RGB로 분할한 영상이다. 일 반적으로 $\mathrm{RED}$ 영상에 화재 정보를 많이 담고 있으므로 이 영상만으로 RED Filtering ${ }^{(9)}$ 하여 화재 영역을 추출하는 방법도 있으나, 이 방법은 화재가 아닌 밝기를 가진 영역 도 화재 영역으로 오인식하는 경우가 있어, 본 논문에서는 $\mathrm{RGB}$ 영역 모두를 활용하는 HSI 변환을 이용한다.

Figure 7은 Figure 6으로부터 식(1), 식(2), 식(3)을 이용 하여 얻은 HSI 영상이다. 식(1)에서 색상(Hue)은 화재로 인식될 수 있는 붉은 색 계열의 색상이며 이것의 범위가 $0^{\circ}$ 또는 $360^{\circ}$ 를 기준으로 $\pm 5^{\circ}\left(10^{\circ}\right)$ 사이의 색상을 화재로 인식한다. 식(2)에서 채도(Saturation)는 순색에 첨가된 백 색광의 비율을 의하며 0 1의 범위를 갖는다. 빛의 세기는 상대적이며 반복실험을 통하여 화재가 발생한 곳의 빛의 세기는 0.7 을 넘었다. 식(3)에서 명도(Intensity)는 빛의 세 기를 의미한다. $0 \sim 1$ 의 범위를 갖으며 0 은 검정, 1 은 흰색 을 의미한다. 본 실험에 사용된 카메라는 10배 Zoom-In/ Out 기능을 가지고 있으며, 원거리(실험상 $100 \mathrm{~m}$ 상에서

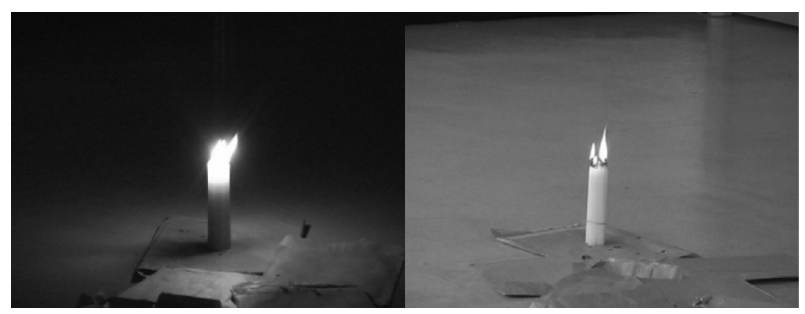

Figure 5. Original nighttime and daytime image. 


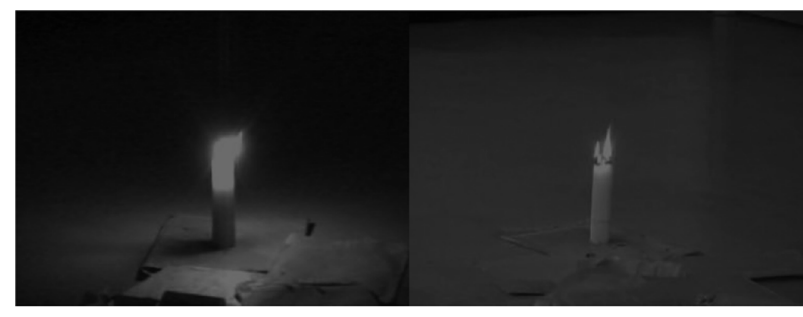

(a) Red image.

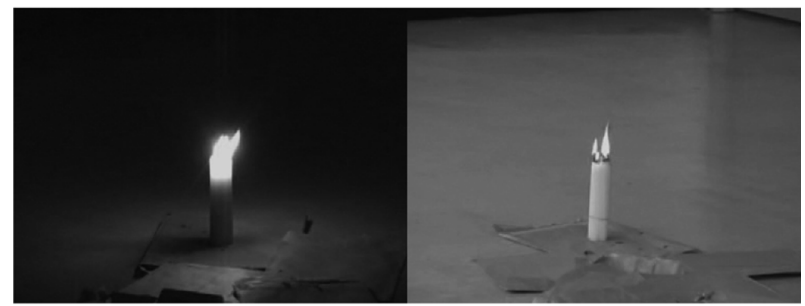

(b) Green image.

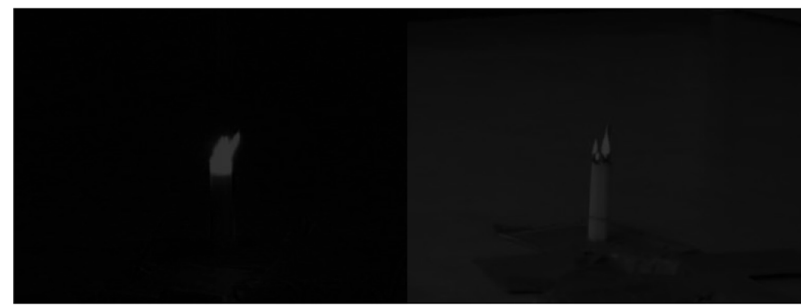

(c) Blue image.

Figure 6. Image of RGB transform.

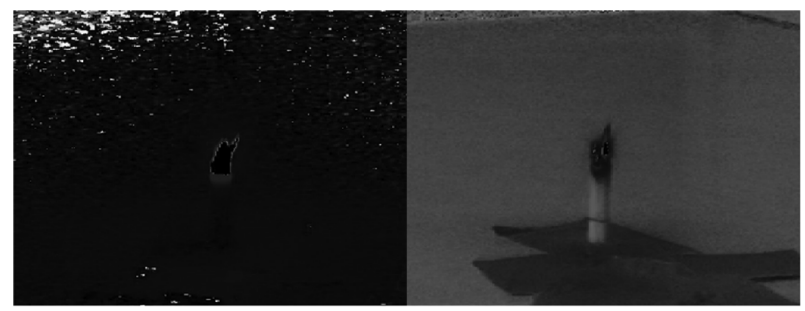

(a) Hue image.

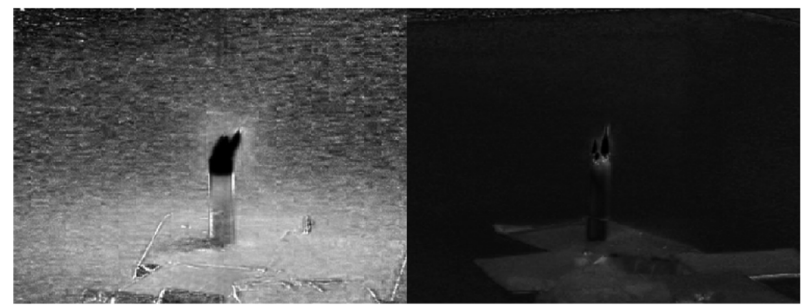

(b) Saturation image.

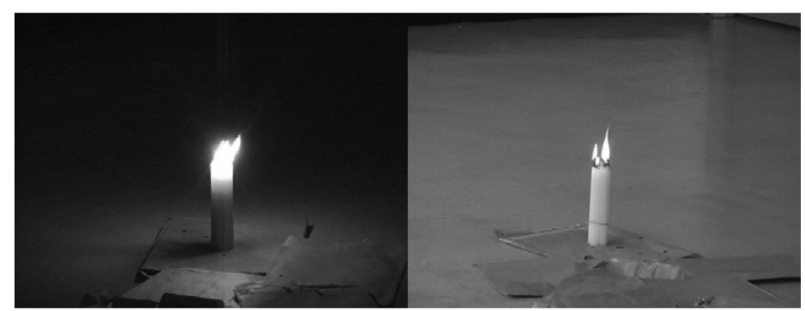

(c) Intensity image.

Figure 7. Image of HSI transform.

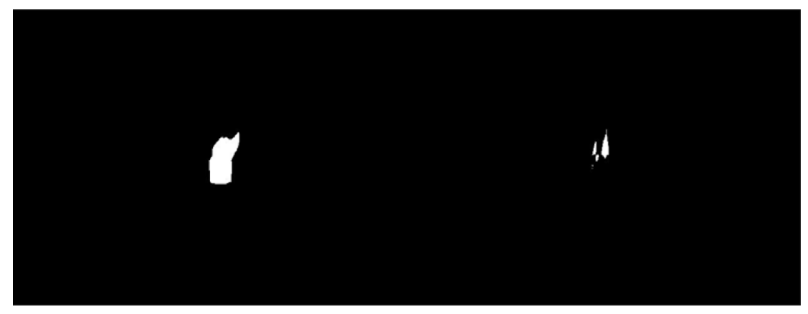

Figure 8. Binary image.

Zoom-In한 거리 : 실제 무보정 $10 \mathrm{~m}$ 거리)에서 화재를 측 정하면 촛불 뭉치의 경우 0.5 이하로 떨어지며, 근거리(실 험상 $30 \mathrm{~m}$ 이내에서 Zoom-In한 거리 : 실제 무보정 $3 \mathrm{~m}$ 거리)에서 화재를 측정하면 0.8 이상의 값을 가진다. 본 실 험에서는 실제 $3 \sim 5 \mathrm{~m}$ 이내의 거리에서 무보정 영상으로 실험하였다.

Figure 8은 HSI변환에 의한 화염 영역 인식 알고리즘을 이용하여 화염 지역을 분할하고 2 진영상으로 나타낸 것이 다. 주변의 밝은 빛들은 화재가 아닌 영역으로 분리되어 모두 제거되었고, 화염이 집중적으로 존재하는 영역만을 분리해내었다.

\section{2 화재영역 추적 및 $\mathrm{Pan} / \mathrm{Tilt}$}

Figure 9는 2진영상으로부터 경계를 검출한 영상이며, Figure 10처럼 Screen 좌표상에서 화재영역이 있는 영역을 Viewport로 정하고 그 영역의 좌상단점을 얻는다. Figure 11 은 이 알고리즘을 통하여 최종적으로 인식된 화염의 위 치를 나타낸 것이다. 이렇게 추출된 화재영역의 좌표값은 $\mathrm{Pan} / \mathrm{Tilt}$ 의 Viewport 값으로 주어지며 카메라가 자동으로 화재가 발생한 영역을 화면의 중심으로 이동시키면서 정 확한 화재 좌표와 그 주변상황을 스마트 모바일 시스템을

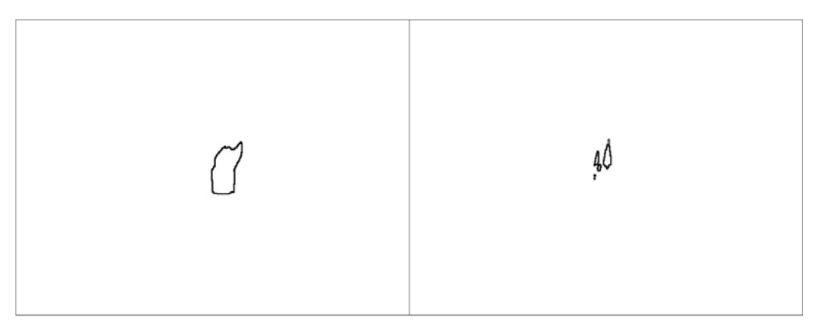

Figure 9. Edge detection image.

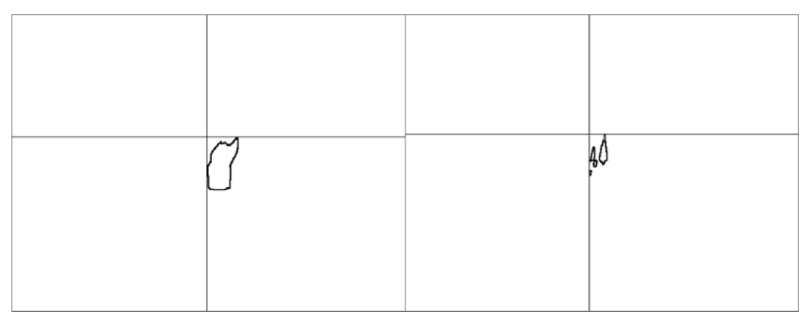

Figure 10. Computing of axises. 


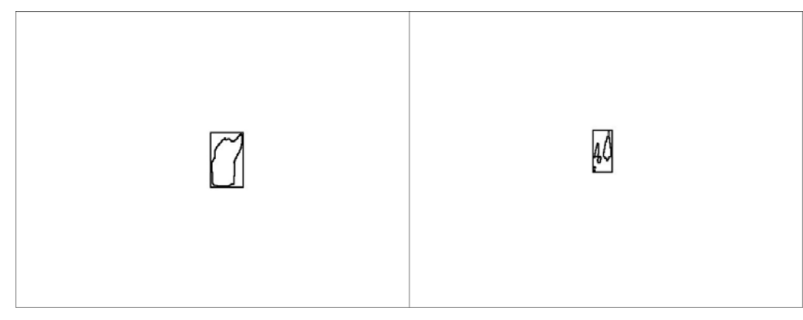

Figure 11. Recognition of fire axises.

통하여 화재 영상 인식 시스템을 제어하는 관리자에게 전 달된다.

Figure 12는 화면상에서는 보이지는 않지만 실제로 화재

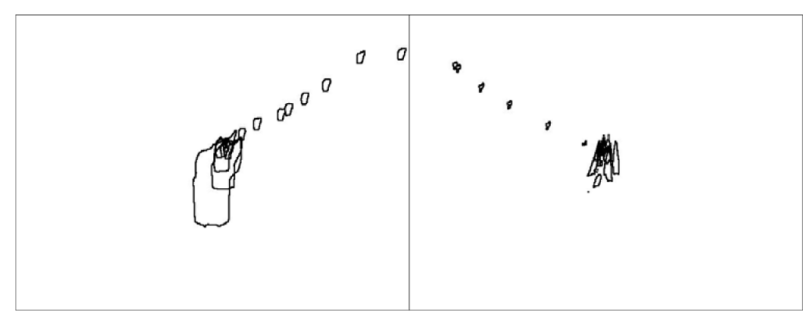

Figure 12. Process of trace with edge detection image.

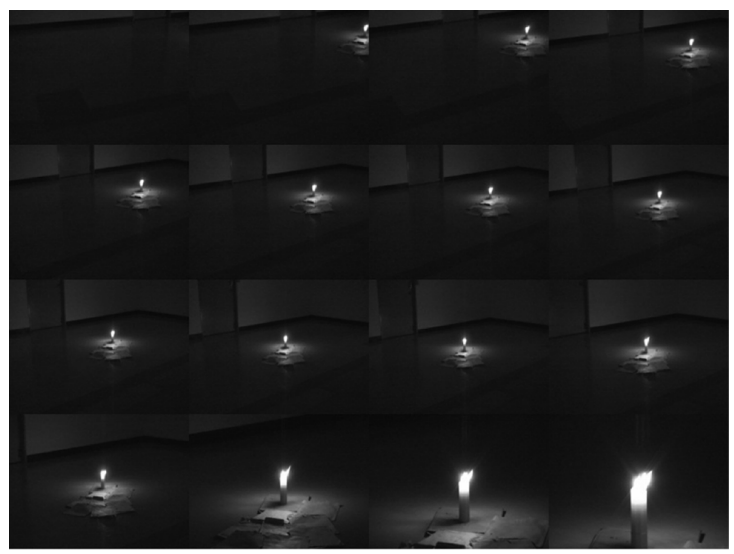

(a) Fire image of nighttime.

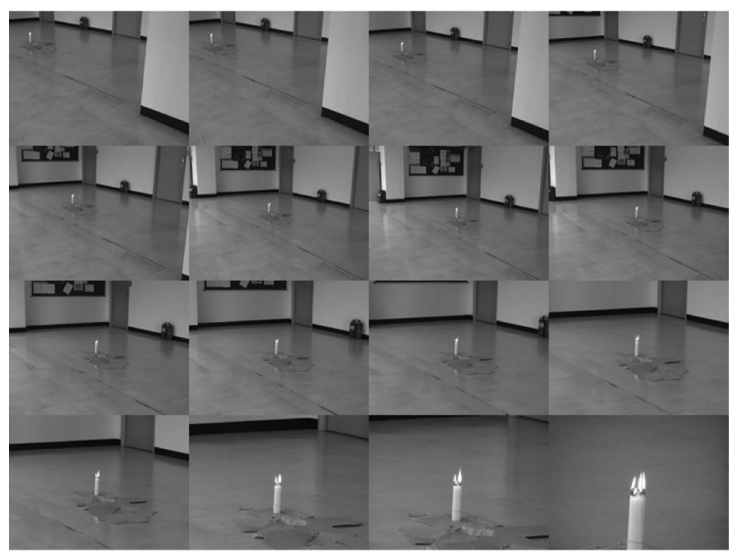

(b) Fire image of daytime.

Figure 13. Process of trace with original image.
가 발생한 초기 상황을 감지하고 계속 화면의 중앙으로 $\mathrm{Pan} / \mathrm{Tilt}$ 하는 과정을 추적한 그림이다. 이 과정과 부합하는 실제 동영상에서의 16 프레임 영상을 연속적으로 나타낸 그림은 Figure 13과 같다.

Figure 13은 주간 화재동영상 6개중에서 하나와 야간 화 재 동영상 4개중에서 하나를 나타낸 것이다. 화재영상 인 식 실험은 실제 화재를 발생시키거나 그와 유사한 어느 규 모 이상의 화재를 발생시켜서 실험을 하는 것이 정상이나, 본 실험에서는 이미 크게 발생한 화재를 인식하는 것이 목 적이 아니고, 화재 발생 초기에 빠르게 그 사실을 인지하 고 적절하게 대응하기 위한 실험으로, 작은 크기의 화염에 대해서만 실험을 하였다. 실험에 사용한 화재동영상은 야 간 화재 동영상 4 개, 주간 화재 동영상 6개를 실험하였으 며, 모두 완벽하게 화재발생 위치를 검출하고 추적하였다. 앞으로 추가로 연구되어야 할 것은 다양한 환경에서 잡음 에 해당하는 다양한 간섭 불빛도 함께 적용하여 실제 작업 장이나 공장 내부, 또는 원자로 내부에서 작은 불씨도 검 출할 수 있는 실험을 하여 그 우수성을 증명하고자 한다.

\section{4. 결 론}

최근 방범 및 보안, 화재감시 목적으로 $\mathrm{CCD}$ 카메라가 많이 사용되고 있고, 특히 유무선 TCP/IP 기능과 Pan/Tilt 기능이 탑재된 $\mathrm{CCD}$ 카메라의 수요가 높아지고 있으며, 본 논문에서는 이 $\mathrm{CCD}$ 카메라를 이용하여 화재 발생 사 실을 인지하고 모바일을 활용하여 원거리에서 적절하게 대응할 수 있는 스마트 화재 인식 시스템을 제안하였다. 이러한 시스템을 구현하기 위하여 본 연구에서는 영상의 $\mathrm{HSI}$ 변환을 통하여 화재 발생 위치 검출 방법을 제안하였 고, Pan/Tilt 기능과 스마트 모바일 기능을 연계하여 화재 발생 장소가 아닌 원거리에서도 화재를 인지하고 대응하 는 시스템을 구성할 수 있도록 하였으며, 화재영상에 대한 인식과 추적 실험을 수행하였다.

기존의 Red Filtering을 이용한 화재 위치 검출은 화재 가 아닌 밝기값에 의해서도 화재로 오인식 할 수 있었으나 영상의 HSI 변환을 이용하여 제안한 알고리즘은 불꽃과 주변의 다른 밝기를 구분하여 불꽃 밝기만을 추출할 수 있 었다.

실험에 사용된 동영상 10 개중에서 모두 화염 영역을 인 식하였으며 화염영역을 추적하기 위한 좌표가 Pan/Tilt를 위한 전송에서 인터넷 환경의 문제로 인하여 전달에 지연 이 생기는 문제는 차후 스마트기능을 완성하기 위해서 보 완해야 할 것이다.

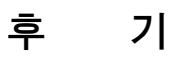

이 논문은 2013년도 가천대학교 교내연구비 지원에 의 한 결과임(GCU-2013-R384). 


\section{References}

1. D. H. Baek and J. W. Kim, "Recognition of Fire Position and Region using Red Filtering and Mask Matching", Journal of Korean Institute of Fire Science and Engineering, Vol. 19, No. 4, pp. 64-68 (2005).

2. B. Ugur Toreyin, Yigihan Dedeoglu, Ugur Gudukbay and A. Enis Cetin, "Computer Vision based Method for Realtime Fire and Flame Detection", Pattern Recognition Letters, Vol. 27, pp. 49-58 (2006).

3. K. H. Cheong, B. C. Kwo and J. Y. Nam, "Vision-based Early Fire Detection System", Journal of Korean Society for Image Science \& Technology, pp. $62-71$ (2006).

4. Rick Kjeldsen and John Kender, "Finding Skin on Color Images", Proceedings of the Second International Conference on Automatic Face and Gesture Recognition, pp. 312-317 (1996).

5. S. Noda and K. Ueda, "Fire Detection in Tunnels using an Image Processing Method", Vehicle Navigation \& Information Systems Conferences Proceedings, pp. 57-62 (1994).

6. G. Healey, D Slater, T. Lon, B. Drha and D. Goedeke, “A System for Real-time Fire Detection", IEEE Computer Society Conference on Computer Vision and Pattern Recognition, pp. 605-606 (1994).

7. J. J. Lee, "Fire Recognition System based on Network Camera", Journal of Korean Society for Imaging Science \& Technology, Vol. 13, No. 4, pp. 233-242 (2007).

8. D. H. Baek and J. W. Kim, "The Study of Fire Detector using Wireless Communication", Journal of Korean Institute of Fire Science and Engineering, Vol. 24, No. 1, pp. 111-115 (2010).

9. S. K. Whang, "Image Process Programming by Visual C++”, Hanbit Midea Inc., Seoul Korea, pp. 594-601 (2011). 